\title{
Selective iodination of 2-acetyl-1-naphthol using iodine and iodic acid under solvent-free grinding technique
}

\author{
Sainath Zangadea,*, Shyam Mokleb, Avinash Shindeb and Yeshwant Vibhute ${ }^{\mathrm{b}}$ \\ a Department of Chemistry, Madhavrao Patil Mahavidyalaya, Palam, Prabhani, Maharashtra, 431720, India \\ ${ }^{\mathrm{b}}$ Laboratory of Organic Synthesis, Department of Studies in Chemistry, Yeshwant Mahavidyalaya, Nanded, Maharashtra, 431602, India \\ *Corresponding author at: Department of Chemistry, Madhavrao Patil Mahavidyalaya, Palam, Prabhani, Maharashtra, 431720, India. \\ Tel.: +91.982.2939699; fax: +91.246.2253726.E-mail address: drsbz@rediffmail.com (S. Zangade).
}

\section{ARTICLE INFORMATION}

Received: 27 May 2012

Received in revised form: 02 June 2012

Accepted: 02 June 2012

Online: 30 September 2012

\section{KEYWORDS}

\section{Iodine}

Iodic acid

Solvent-free

Grinding technique

Selective iodination

2-Acetyl-1-naphthol

\section{Introduction}

Aromatic iodo compounds are valuable and versatile synthetic intermediates in organic chemistry [1]. They are useful for the preparation of organometallic reagents, and some are potential intermediates for the synthesis of pharmaceutical and bioactive materials $[2,3]$. They are also important and the most reactive intermediates for various cross-coupling reactions and especially useful for formation of carbon-carbon and carbon-heteroatom bonds [4]. Recently the reagents reported for iodination of arenes include, iodine-nitrogen dioxide [5], iodine F-TEDA-[1-chloromethyl-4-fluoro-1,4diazoniabicyclo [2,2,2] octane-bis-(tetrafluoroborate)] [6], bis$\mathrm{N}$-iodosuccinimide [7], trichloroisocyanuric acid- $\mathrm{I}_{2}-\mathrm{Wet} \mathrm{SiO}_{2}$ [8], mercury(II)-oxide-iodine [9], iodine-monochloride [10], bis(pyridine)iodonium(I), tetrafluoroborate $\mathrm{CF}_{3} \mathrm{SO}_{3} \mathrm{H}$ [11], NIS$\mathrm{CF}_{3} \mathrm{SO}_{3} \mathrm{H}$ [12], iodine silver sulfate [13], iodine-mercury salts [14] and NaOCl-NaI [15]. However, most of these methods suffer from major drawbacks such as use of harsh conditions, toxic heavy-metal catalysts, non-slectivity and longer reaction times. Use of iodine in combination with iodic acid found to be an efficient iodinating agent for iodination for aromatic compounds. In view of these observations we report here the selective iodination of 2-acetyl-1-naphthol (bicyclic arene) using iodine and iodic acid under solvent-free environment using grinding technique (Scheme 1).

\section{Experimental}

\subsection{Instrumentation}

Melting point was determined in an open capillary tube and is uncorrected. IR spectra were recorded in $\mathrm{KBr}$ pellets on a Shimadzu FT-IR spectrometer. ${ }^{1} \mathrm{H}$ and ${ }^{13} \mathrm{C}$ NMR spectra were obtained in DMSO- $d_{6}$ on Avance $300 \mathrm{MHz}$ spectrometer using TMS as an internal standard. The mass spectra were recorded on EI-Shimadzu-GC-MS spectrometer. Elemental analyses were performed on a Carlo Erba 106 Perkin-Elmer model 240 analyzer.

\subsection{Synthesis}

Mixture of 2-acetyl-1-naphthol (50 mmol), iodine (20 $\mathrm{mmol}$ ), taken in open mortar and grind with pestle for $2 \mathrm{~min}$. To this reaction mixture saturated solution of iodic acid (10 mmol) was added and grinding was continued up to disappearance of reactant spot on thin layer chromatography (TLC). After completion of grinding saturated solution of $\mathrm{Na}_{2} \mathrm{~S}_{2} \mathrm{O}_{3}(10 \mathrm{~mL})$ was added to remove excess of iodine to obtained solid product. Resultant solid product was filtered through simple büchner funnel, washed with cold water and crystallized from ethanol to yield 1-(1-hydroxy-4-iodonaphthalen-2-yl)-ethanone (Scheme 1). The purity of compound was checked by TLC, using hexane/ ethyl acetate as the mobile phase.

1-(1-Hydroxy-4-iodo-naphthalen-2-yl)-ethanone: Color: Light greenish. Yield: 94\%. M.p.: $156^{\circ} \mathrm{C}$. FT-IR $\left(\mathrm{KBr}, v, \mathrm{~cm}^{-1}\right)$ : $3070,1726,1622,1583,1494,1442,1411,1232,831,759 .{ }^{1} \mathrm{H}$ NMR $\left(300 \mathrm{MHz}\right.$, DMSO- $\left.d_{6}, \delta, \mathrm{ppm}\right): 14.0(\mathrm{~s}, 1 \mathrm{H}, \mathrm{OH}), 8.2(\mathrm{~s}, 1 \mathrm{H}$, Ar-H), 8.4-7.2 (m, 4H, Ar-H), 2.7 (s, 3H, $\left.\mathrm{CH}_{3}\right) .{ }^{13} \mathrm{C}$ NMR $(75 \mathrm{MHz}$ DMSO- $d_{6}, \delta, \mathrm{ppm}$ ): 196.24 (C of $\mathrm{C}=0$ ), 156.35 (C of Ar-OH), 137.63 (C of Ar-C), 135.37 (C of Ar-C), 132.73 (C of Ar-C), 131.86 (C of Ar-C), 129.70 (C of Ar-C), 127.48 (C of Ar-C), 124.58 (C of Ar-C), 120.14 (C of Ar-C), 93.89 (C of Ar-I), 24.17 (C of $\mathrm{CH}_{3}$ ). MS (EI, $m / z(\%)$ ): $312\left(\mathrm{M}^{+}, 100\right), 297$ (60), 294 (20), 269 (10), 241 (20), 186 (5), 167 (10), 142 (20), 128 (40), 114 (65), 74 (20), 63 (30). Anal. calcd. for $\mathrm{C}_{12} \mathrm{H}_{9} \mathrm{O}_{2} \mathrm{I}: \mathrm{C}, 46.15$; $\mathrm{H}$, 2.88. Found: $\mathrm{C}, 45.18 ; \mathrm{H}, 2.86 \%$. 


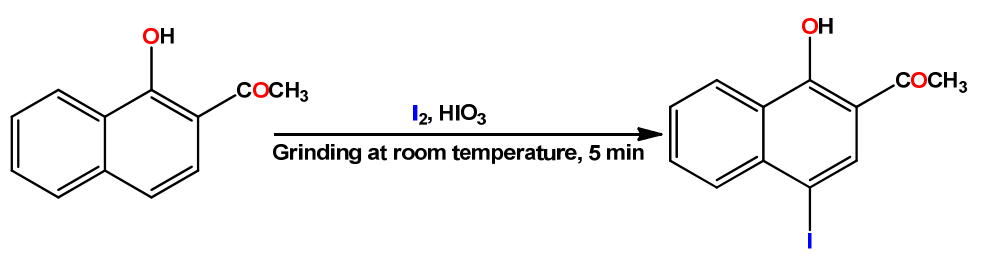

Scheme 1

\section{Result and discussion}

In continuation of earlier research work [16-19], we report here in a simple, rapid, efficient and environmentally benign solvent-free iodination of 2-acetyl-1-naphthol using iodine and iodic acid in combination with grinding at room temperature. The iodination occur selectively at electron rich centre i.e. paraposition to $-\mathrm{OH}$ group. The corresponding product 1-(1hydroxy-4-iodo-naphthalen-2-yl)-ethanone obtained in $94 \%$ yield. In grindstone technique, reaction occurs through generation of local heat by grinding of crystals of substrate and reagent. Reactions are initiated by grinding, with the transfer of very small amount of energy through friction. Such reactions are simple to handle, reduce pollution, comparatively cheaper to operate and may regarded as more economical and ecologically favorable procedure in chemistry [20]. Obtained iodo product established on the basis of spectral characterization, IR, ${ }^{1} \mathrm{H}$ NMR, ${ }^{13} \mathrm{C}$ NMR, MS, and elemental analysis.

\section{Conclusion}

In summary, we have described selective iodination of 2-acetyl-1-naphthol using iodine and iodic acid under solventfree grindstone technique.

\section{Acknowledgements}

The authors gratefully acknowledge University Grant Commission (UGC) New Delhi for sanctioning major research grant (No. 38-267/2009). The authors are also thankful to Principal, Yeshwant Mahavidyalaya, Nanded, for providing laboratory facilities and Director Indian Institute of Chemical Technology (IICT), Hyderabad, for providing necessary instrumental facilities.

\section{References}

[1]. Diederich, F.; Stang, P. J. Metal-Catalyzed Cross Coupling Reactions; Wiley-VCH: Weinheim, Germany, 1998.

[2]. Seevers, R. H.; Counsell, R. Chem. Rev. 1982, 82, 575-590.

[3]. Alonso, F.; Beletskaya, I. P.; Yus, M. Chem. Rev. 2002, 102, 4009-4092.

[4]. Olivera, R.; San Martin, R.; Dominguez, E. Tetrahedron Lett. 2000, 41, 4357-4360.

[5]. Noda, Y.; Kashima, M. Tetrahedron Lett. 1997, 38, 6225-6228.

[6]. Zupan, M.; Iskra, J.; Stavber, S. Tetahedron Lett. 1997, 38, 6305-6306.

[7]. Carreno, M. C.; Ruano, J. G.; Sanz, G.; Toledo, M. A.; Urbano, A. Tetrahedron Lett. 1996, 37, 4081-4084.

[8]. Akhlaghinia, B.; Rahmani, M. Turk. J. Chem. 2009, 33, 67-72.

[9]. Orito, K.; Hatakeyama, T.; Takeo, M. Synthesis 1995, 1273-1277.

[10]. Hubig, S. M.; Jung, W.; Kochi, J. K. J. Org. Chem. 1994, 59, 6233-6244.

[11]. Barluenga, J.; Gonzalez, J. M.; Garcia-Martin, M. A.; Campos, P. J.; Asensia, G. J. Org. Chem. 1993, 58, 2058-2060.

[12]. Olah, G. A.; Wang, D.; Sandford, G.; Prakash, G. K. S. J. Org. Chem. 1993, 58, 3194-3195.

[13]. Sy, W. W. Tetrahedron Lett. 1993, 34, 6223-6224.

[14]. Bachki, A.; Foubelo, F.; Yus, M. Tetrahedron 1994, 50, 5139-5146

[15]. Edgar, K. J.; Falling, S. N. J. Org. Chem. 1990, 55, 5287-5291.

[16]. Zangade, S.; Mokle, S.; Chavan, S.; Vibhute, Y. Orbital Elec. J. Chem. 2011, 3, 144-149.

[17]. Zangade, S.; Shinde, A.; Patil, A.; Vibhute, Y. Eur. J. Chem. 2012, 3, 208210.
[18]. Zangade, S.; Shinde, A.; Vibhute, A.; Vibhute, Y. Pak. J. Chem. 2012, 2, 18-23.

[19]. Shinde, A. T.; Zangade, S. B.; Chavan, S. B.; Vibhute, A. Y.; Nalwar, Y. S. Vibhute, Y. B. Synth. Commun. 2010, 40, 3506-3513.

[20]. Bose, A. K.; Pednekar, S.; Ganguly, S. N.; Chakraborty, G.; Manhas, M. S. Tetrahedron Lett. 2004, 45, 8351-8353. 